\title{
Retraction Note: On eigenstructure of $q$-Bernstein operators
}

\author{
Ambreen $\mathrm{Naaz}^{1} \cdot$ M. Mursaleen ${ }^{1,2}$ (D) \\ Published online: 15 May 2021 \\ (c) Springer Nature Switzerland AG 2021
}

\section{Retraction Note to: Analysis and Mathematical Physics (2021) 11:6 https://doi.org/10.1007/s13324-020-00443-7}

The Editor in Chief has retracted this article because it contains sections that substantially overlap with an article published by different authors [1]. In addition, severe gaps in the proofs of the main results of the paper were found post-publication.

The authors have agreed to this retraction but not to the wording of this retraction notice.

\section{References}

1. Cooper, S., Waldron, S.: The eigenstructure of the Bernstein operator. J. Approx. Theory 105, 133$162(2000)$

Publisher's Note Springer Nature remains neutral with regard to jurisdictional claims in published maps and institutional affiliations.

The original article can be found online at https://doi.org/10.1007/s13324-020-00443-7.

M. Mursaleen

mursaleenm@gmail.com

Ambreen Naaz

naaz.ambreen11@gmail.com

1 Department of Mathematics, Aligarh Muslim University, Aligarh 202002, India

2 Department of Medical Research, China Medical University Hospital, China Medical University (Taiwan), Taichung, Taiwan 